\title{
Research on Green Building Design Pattern
}

\author{
Zhou Yi \\ Tong Zhi street No.3066 School of Architecture \&. Design, Changchun Institute of Technology. \\ Changchun City Jilin Prov. China, 130021 \\ 403676035@qq.com
}

Keywords: The Green Building ; building life cycle; IDP; linear design pattern; radioactive design pattern ; Co-Design

Abstract. Green building has rapidly developed since it entered the Chinese construction market. But the design pattern and the design method is not suitable for some problems. This paper studied the design process, Personnel cooperation and advanced information technology sharing three aspects, and explored suitable architectural design pattern for China's green buildings.

\section{Introduction}

Green Building Logo Project Bulletin from Ministry of Housing and Rural Development of the People's Republic of China Statistics Show: "From April 2008 to the end of 2015, the total number of national green building logo project has 3636, of which a total of 1766 residential buildings, accounting for more than 48.6\%". China in the "the 13th Five-Year Plan" clearly stressed the speed up the promotion of China's green building policy incentives.

National policy support, coupled with the advancement of local governments, green building should have been carried out smoothly and quickly occupied the construction market, but this is not the case. In the green building design, there are three main problems: First, the design process is cumbersome, architectural design is still in accordance with the previous design methods and models to do, and then by the green building consulting firm under the "Assessment standard for green building" for the second design, add the evaluation of the score after the design to modify. Second, there are some deviation between the design and the actual completion. The actual construction is not done according to the original design, after that won the Star Green Building. Third, some buildings, those won the Green Building Design Star, do not energy-saving instead more waste because of using a lot of unsuitable green technology. The main reason for the above problems is that the traditional design pattern is not suitable for green building design. Green buildings should adopt design patterns in line with its characteristics.

\section{Green Building}

\section{The Meaning of Green Building}

According to "Assessment standard for green building" GB-T50378-2014, the definition of green building is as follows: Green building refers to building life cycle, the maximum conservation of resources (energy, land, water and materials), protecting the environment and reducing pollution, providing people with healthy, appropriate and efficient use of space, and nature harmony of the building. [1] Building life cycle refers to the whole process from the early decision-making, design, construction, completion, to the use, maintenance, repair, and then the final demolition. The Green Building practice expands and complements the classical building design concerns of economy, 
utility, durability, and comfort.[2]

\section{Green Building features}

Compared with ordinary buildings, green building not only has the common features of residential buildings, safety, health, economy, but also has the following characteristics:

(1) Green building is in harmony with the environment, and adjusts Measures to Local Conditions. From planning to design, fully consider the harmony with the natural environment climatic conditions and the symbiosis, make full use of the original terrain and land. From construction to use, it minimizes the impact of the environment, the destruction of the ecological. From the maintenance, repair to the transformation, the demolition of the entire life cycle, it is to maximize recycling and waste recycling.

(2) Green building is healthy and comfortable for users. It means to make full use of technical method to meet the comfort of people's lives: including indoor air quality, temperature and humidity, sound environment, light environment, etc., at the same time to achieve intelligent and adjustable function in parallel, not only to achieve intelligent savings but also to meet the needs of human active energy-saving behavior.

(3) It is economical and sustainable. Energy saving is mainly reflected in two aspects of broaden sources of energy \& Reduce energy expenditure. "broaden sources" is mainly to make full use of renewable energy, including wind power, hydropower, solar power, geothermal energy, bio energy. "Reduce energy expenditure" is mainly to reduce unnecessary waste of nonrenewable energy, including water saving, land saving, material saving. Water saving is mainly reflected in the use of classification, and purification and reuse. Land Saving is means to make full use of the land which can be constructed to reduce the over exploitation of the land and make it recoverable. Material saving, in terms of material itself, is to use renewable and recyclable materials; In terms of architectural design, is to reduce the space decoration and big and improper, choosing the proper structure and tectonic process.

Green building design is no longer a single to "function", "space" and "shape" as the goal, but to "green", "energy saving", "comfortable" as the premise, to meet the reasonable function, space, form fitting. [3]

\section{The problem of green building design in traditional design mode}

At present, the process of building design is generally divided into several stages, those are pre-design consultation, architecture design, construction drawing design, construction, delivery, interior design and using and management. Each stage presents a "linear" process and in turn (refer with: Fig. 1). And each major is in different stages into the design process. The traditional mode of cooperation is based on the major of architecture, and the other is supplemented.

Architectural design is the first step, MEP design is in the construction phase of the design phase, and the interior design is completed after the completion of the building. The designers of

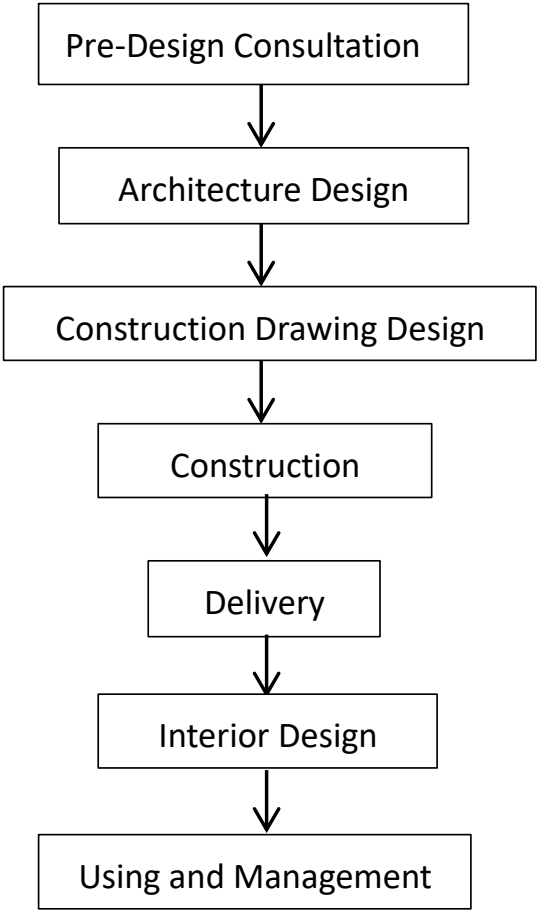

Fig. 1 Linear design patterns each stage design from their own point of view.

The green building design is a holistic. According to its characteristics, the subsequent design of each stage must be considered at the beginning of the design, and collaborative work and effective 
delivery of information are also considered. When the traditional time - dependent design pattern (refer with: Fig. 1) in response to green building design, there will be the following problems: (1) repeat design; (2) changes because of poor coordination; (3) a waste of energy resources and owner funds; (4) inefficiency. Therefore, the green building should explore a design pattern in line with its characteristics.

\section{The exploration and research on the green building design pattern}

“IDP"

IDP (Integrated Design Process) was used in the early 1990s, by Canada's C-2000 programs. It is a method for realizing high performance buildings that contribute to sustainable communities. It is a collaborative process that:

(1) Focuses on the design, construction, operation and occupancy of a building over its complete life-cycle.

(2) is designed to allow the client and other stakeholders to develop and realize clearly defined and challenging functional, environmental and economic goals and objectives

(3) includes a multi-disciplinary design team that includes or acquires the skills required to address all design issues flowing from the objectives

(4) Proceeds from whole building system strategies working through increasing levels of specificity so as to realize more optimally integrated solutions. [3]

IDP and the traditional design process are different from the think of the building as a whole, focus on life cycle design and work together as a team from the beginning.

\section{Radioactive design pattern}

Compared with the development of green building in developed countries, China's green building development of the road is very different. The development of green building in developed countries comes from the green technical maturity, but in China comes from the future development of the country. In addition, the operation mode of foreign construction industry is different from that of china. Completely copy the foreign green building design pattern is not reasonable.

Radioactive design pattern is an innovative design pattern, In view of the problems existing in the green building in China, using IDP for reference; this paper expounds the research achievements of the radioactive design pattern from the following three aspects:

(1) The design process, that is the "radioactive" process, not the original "linear" model. (Refer with: Fig. 2) According to the instruction of the decision maker, the professional designers work in accordance with the continuous adjustment of the project and the depth of the design, and participate in different degrees according to the priority at the same time. In this way, the repeated design is avoided, the time is saved, and the human resource is saved. 
(2) Personnel coordination, (refer with: Fig. 2) that is based on the central decision makers, the feedback to the center of the information based on the design staff. The central decision maker is

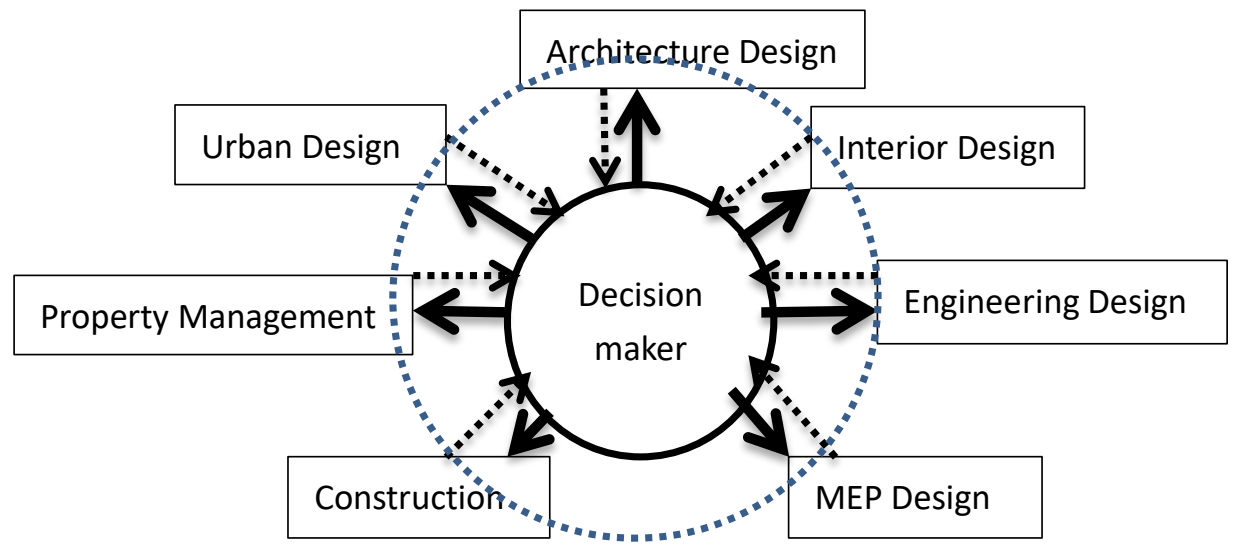

Fig. 2 Radioactive design patterns

not a person, but a team, by the user (or user commissioned professionals), the professional green engineer or green chief engineer, cost personnel composition. Central decision makers make choices and decisions, and issue instructions to each endpoint. Meanwhile, according to the specific design problems, each endpoint can provide the decision maker with optional design items. In order to make the center decision makers can choose the most suitable scheme from the point of view of convenient use, energy saving and emission reduction and economic rationality. Collaborative design is adopted between the endpoints, and the priority is determined by the current norms and decision makers when the collision occurs. Thus, the whole process avoids more changes and modifications.

(3) Communication and sharing of Information and technology, which forms an "internet + building" approach. We use the network platform for information sharing and collaborative design. At this stage, the procurement and bidding of materials can use this model. But the technical field and design field still cannot be achieved until the relevant law and the system perfected.

\section{Conclusions}

Green building project design is different from the previous architectural design, it is more emphasis on the whole life of energy saving and environmental protection and comfort and health, at the beginning of the design to consider the use, maintenance and repair, demolition, reuse. It may also be in the design of the building has not yet formed before the start of some energy-saving environmental protection technology design. "Radioactive" design patterns address these issues. The development of green building will bring the innovation and perfection of the design pattern. This model looks forward to the test of practice, need to supplement and optimize.

\section{References}

[1] "Assessment standard for green building" GB-T50378-2014, Beijing:China Building Industry Press, 2014

[2] Information on http://www.edgebuildings.com

[3]Definition derived from International Energy Agency (IEA) Task 23 and modified at IDP Practitioners Workshop, Oct. 2001, Toronto. [edited by: Nils Larsson, NRCan] 